\title{
CADOProSys Software. Logistics
}

\author{
Cătălin-Iulian Chivu ${ }^{1}$, Catrina Chivu, ${ }^{1, *}$, and Cristina Găvruş ${ }^{1}$ \\ ${ }^{1}$ Engineering and Industrial Management Department, Transilvania University of Brasov, 500174 \\ Mihai Viteazu, Brasov, Romania
}

\begin{abstract}
CADOProSys Software was developed by a group of teachers from Engineering and Industrial Management Department of Transilvania University of Brasov, Romania. The main purpose of software is to help the beginners and graduates to design production systems in the field of automotive industry. CADOProSys Software has many modules. One of these modules is focused on logistics, from suppliers and customers point of view. Starting a production system implies the selection of suppliers from many points of view. The user of the module is able to introduce the criteria and the importance of each criterion. Based on these the modules will provide the appropriate supplier and the inquiry documents.
\end{abstract}

\section{Introduction}

\subsection{Logistics: meaning and evolution}

Logistics is being recognized as a very important factor for major corporations to significantly increase shareholder and customer value. There were lots of definitions for logistic, but one of the most simple and complex in the same time is that given by Edward Frazelle, according to whom "logistics is the flow of material, information, and money between consumers and suppliers" [1].

Starting to " 50 s logistics expanded its meaning (figure 1). Thus, from workplace logistics to global logistics, the concept developed from material handling between workstations to flow of material, information and money between countries.

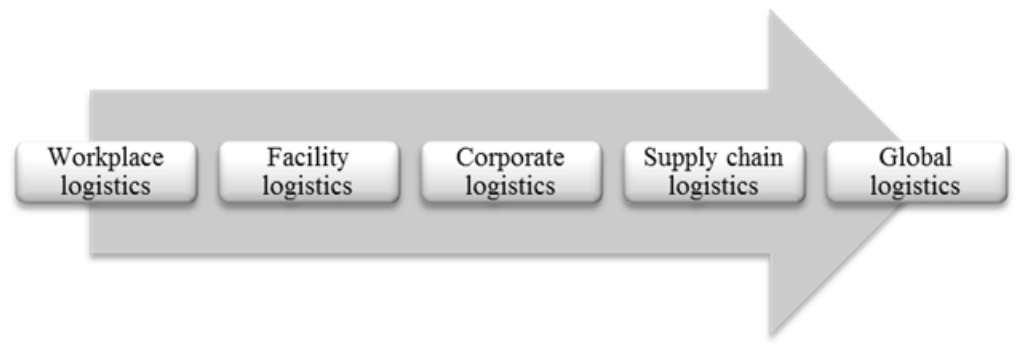

Fig. 1. Logistics evolution.

\footnotetext{
* Corresponding author: catrina.c@unitbv.ro
} 
There are five independent activities that define logistics: customer satisfaction, inventory planning and management, supply, transportation and warehousing (figure 2).

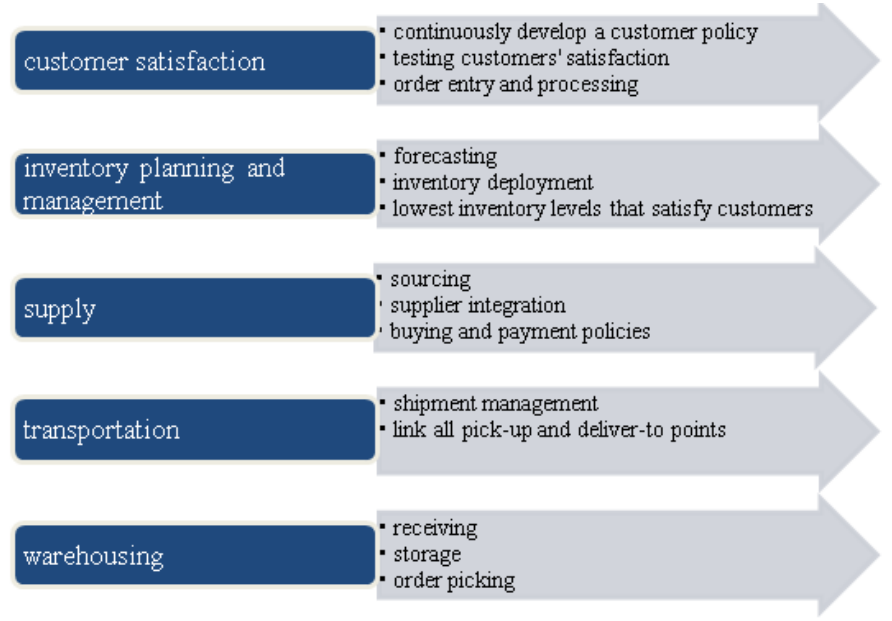

Fig. 2. Logistics activities.

\subsection{Logistics software: market solutions}

There are on the market lots of software oriented on different activities of logistics. According to site Software advice [2], the best rated logistics software are presented in Table 1.

Table 1. Logistics software [2].

\begin{tabular}{|l|l|l|l|l|}
\hline No. & Software & Firm type $^{1}$ & Platform & Price $^{2}$ \\
\hline 1. & Freightview & S, M, L & Mac OS, Windows, Linux & $*$ \\
\hline 2. & U Route & S, M & Mac OS, Windows, Linux & $*$ \\
\hline 3. & SAP - SCM & L & Mac OS, Windows, Linux & $* * * * *$ \\
\hline 4. & UltraShipTMS & S, M, L & Mac OS, Windows, Linux & $* * *$ \\
\hline 5. & S2K Warehouse Management Software & S, M, L & Mac OS, Windows, Linux & $* * * *$ \\
\hline 6. & ShippersEdge & S, M & Mac OS, Windows, Linux & $*$ \\
\hline 7. & LogFire & S, M, L & Mac OS, Windows, Linux & $*$ \\
\hline 8. & Cadence WMS & S, M, L & Mac OS, Windows, Linux & $* * * * *$ \\
\hline 9. & WISE & S, M & Mac OS, Windows, Linux & $* * * *$ \\
\hline 10. & LeanTMS & S, M, L & Mac OS, Windows, Linux & $* * * * *$ \\
\hline
\end{tabular}

${ }^{1} \mathrm{~S}=$ small; $\mathrm{M}=$ =medium; $\mathrm{L}=$ large

$2 *=$ low, $5^{*}=$ very expensive

Analysing de properties of the top ten logistics (figure 3) software it can be underlined that none of this software has a module for new companies, to select the appropriate supplier based on the technical properties of the products. There are no modules oriented to supplier offer, to automatically introduce the offer (based on particularised inquiry) and only two of them are designed for automotive industry.

Selecting the right suppliers becomes even more critical where the organizational strategy is to reduce its supply base and thereby deal with a smaller number of selected vendors. It is vital that the reasons for sourcing and supplier selection should follow agreed vendor appraisal criteria [3]. 


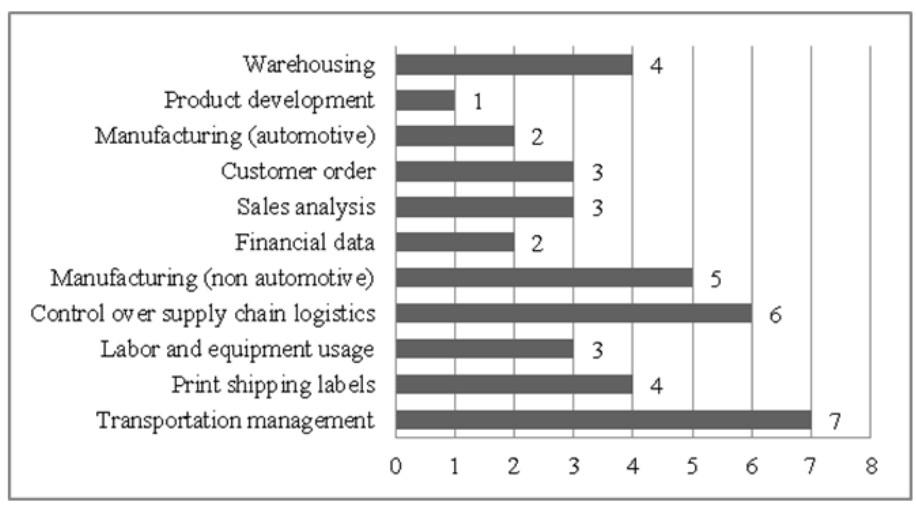

Fig. 3. Characteristics of market logistics software.

\section{CADOProSys logistics module}

Logistics module was developed [4-6] based on the market research of existing software and curriculum of undergraduates. Thus, the authors believed that the logistics module should have the structure presented in figure 4.

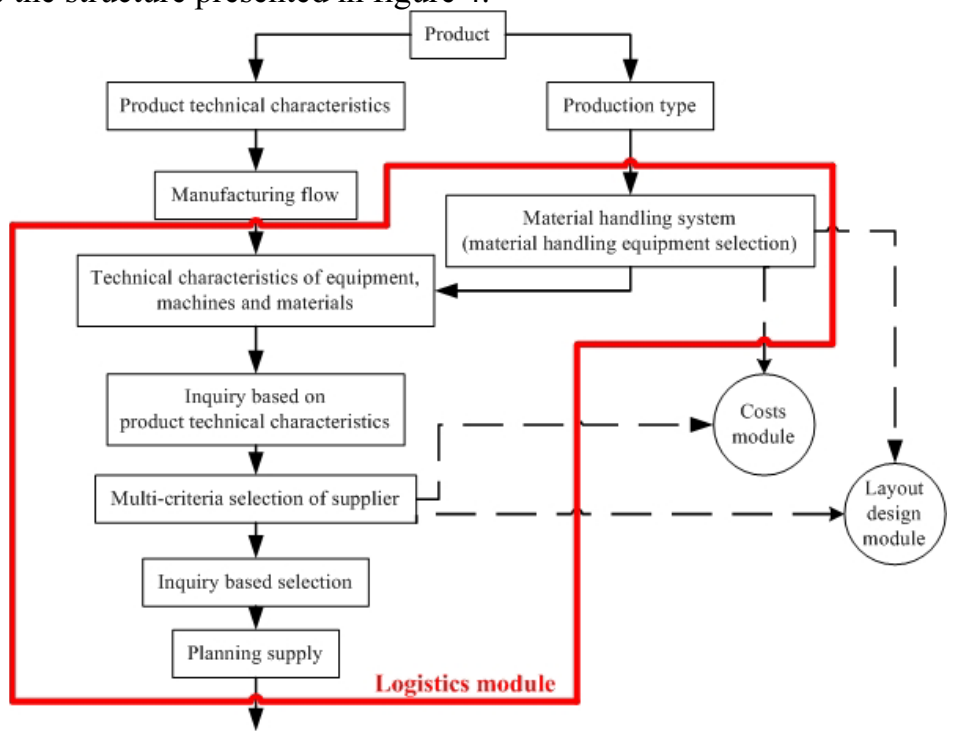

Fig. 4. Logistics module of CADOProSyst.

Designer of the production system is able to introduce the technical requirements for each component: raw material, materials, machine-tools, machines, material handling equipment, etc. Based on these data it is generated the target specifications matrix.

The selection of the supplier is done based on multi-attribute utility theory (MAUT) [710]. This theory is one of the most applied due to its ability to take into account both qualitative and quantitative factors, influencing supplier selection in the presence of risk and uncertainty. One of its advantages is the large number of potential suppliers (up to 500 prospective suppliers) and supplier selection attributes (up to 100 different attributes) that can be handled. The method rigorously measures value by identifying what is important (hierarchy), identifying relative importance (weights), identifying how well each alternative 
does on each criterion (score). The final value may be obtained either linearly or nonlinearly. CADOProSys allows the user to define hierarchy, weights and score, and the final value is determined automatically.

\section{CADOProSys logistics application}

Even if CADOProSys Software was developed especially for automotive industry, some of its modules may be used for any industry (there are module where some coefficients are those specific to automotive industry). Such a module is one focused on selection of suppliers. Thus, in the following, are presented the steps and results of using CADOProSys - Logistics Software for selection of organic cotton supplier, raw material used in a production system of ergonomic baby carriers.

First is generated the data sheet with product technical specification (figure 5a). This data sheet is send electronically to the suppliers, but it can be also generated as Excel sheet (figure 5b).

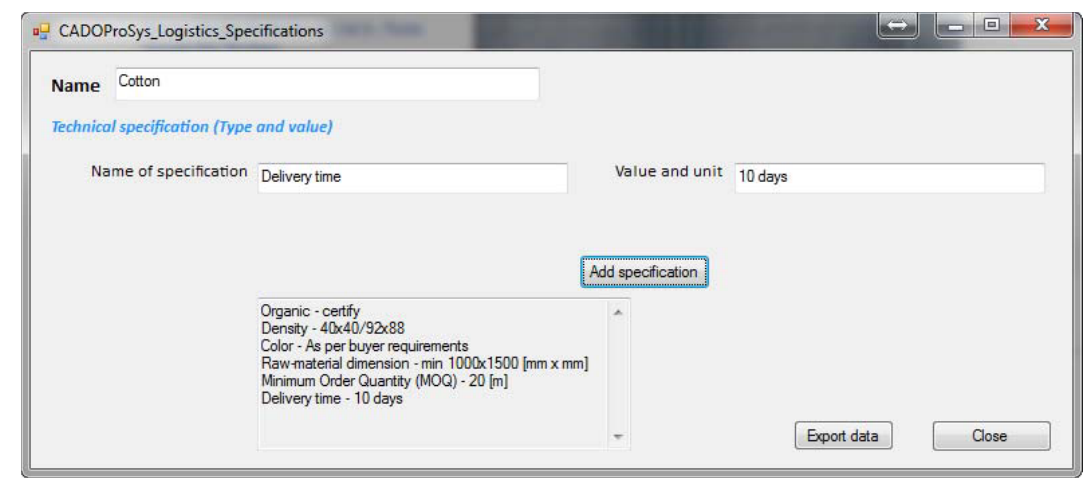

a)

\begin{tabular}{|r|l|l|}
\hline \multicolumn{1}{|c|}{ A } & \multicolumn{1}{c|}{ B } \\
\hline 1 & Name of product & cotton \\
\hline 2 & Specification name & Value and unit \\
\hline 3 & Organic & certify \\
\hline 4 & Density & $40 \times 40 / 92 \times 88$ \\
\hline 5 & Color & As per buyer requirements \\
\hline 6 & Raw-material dimension & min $1000 \times 1500$ [mm $\times \mathrm{mm}]$ \\
\hline 7 & Minimum Order Quantity (MOQ) & 20 [m] \\
\hline 8 & Delivery time & 10 days \\
\hline 9 & & \\
\hline 14 & & \\
\hline
\end{tabular}

b)

Fig. 5. Logistics module of CADOProSyst applied for organic cotton suppliers' selection: a) electronic data sheet; b) Excel data sheet.

Based on the above sheet (either on-line filled or Excel sheet) the next step is to upload data from each supplier in the selection module (a windows as that in figure 6 for each supplier). 


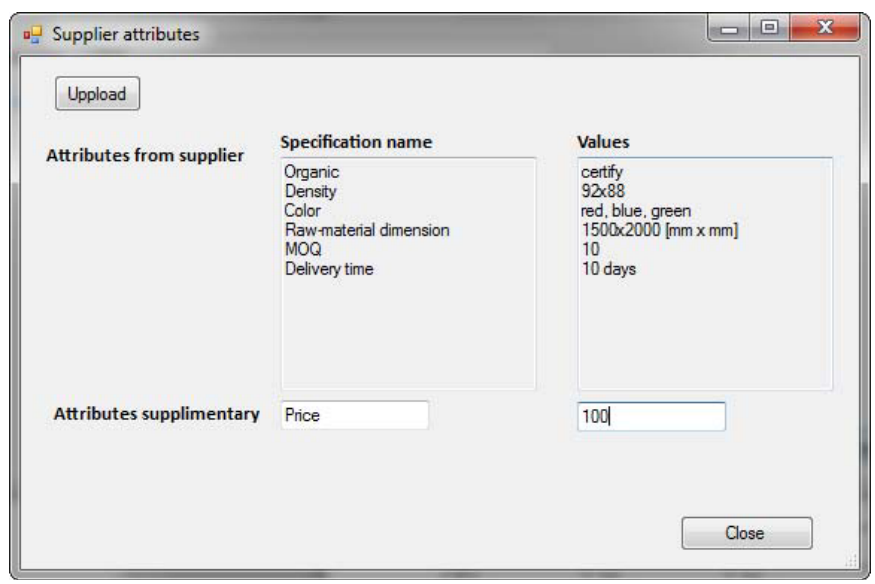

Fig. 6. Supplier attributes.

After all suppliers are defined from attributes point of view is generated a synthesis with the attributes and values (Figure 7).

\begin{tabular}{|c|c|c|c|c|c|}
\hline \multicolumn{5}{|c|}{$\square$ Suppliers attributes and value } & \begin{tabular}{l|l|l|}
$口$ & a & $x$ \\
\end{tabular} \\
\hline Supplier Attributes & $\begin{array}{c}\text { Price } \\
{[1 \mathrm{ei} / 0,5 \mathrm{~m}]}\end{array}$ & $\begin{array}{l}\text { Delivery time } \\
\text { [days] }\end{array}$ & $\begin{array}{l}\text { Distance to supplier } \\
{[\mathrm{km}]}\end{array}$ & Product quality & $\begin{array}{l}\text { Payment } \\
\text { [days] }\end{array}$ \\
\hline S1 & 25 & 20 & 850 & 3 & 45 \\
\hline S2 & 23 & 25 & 700 & 2 & 60 \\
\hline S3 & 20 & 15 & 270 & 1 & 75 \\
\hline S4 & 20,5 & 15 & 420 & 2 & 45 \\
\hline S5 & 23,61 & 10 & 400 & 2 & 30 \\
\hline & & & Generate utilities & Close & \\
\hline
\end{tabular}

Fig. 7. Supplier attributes and values.

User is requested to define the weight on each attribute and the software will compute the score based on the values of the attribute with the highest weight (Figure 8).

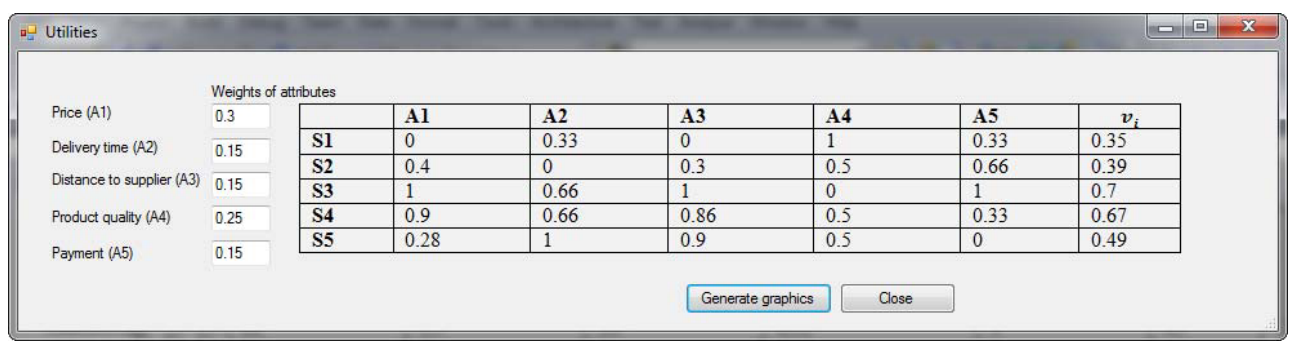

Fig. 8. Utilities.

CADOProSys - Logistics offers the possibility to obtain graphic representation of the results for the total value of utility (scores) but also charts per each attributes (Figure 9). Thus, based on the results shown in Figure 9, the optimum supplier, with higher utility score is S3, but this supplier did not obtained the highest score on each attribute. Thus, based on importance, on management policy, the firm may choose other supplier that satisfies better one attributes. 


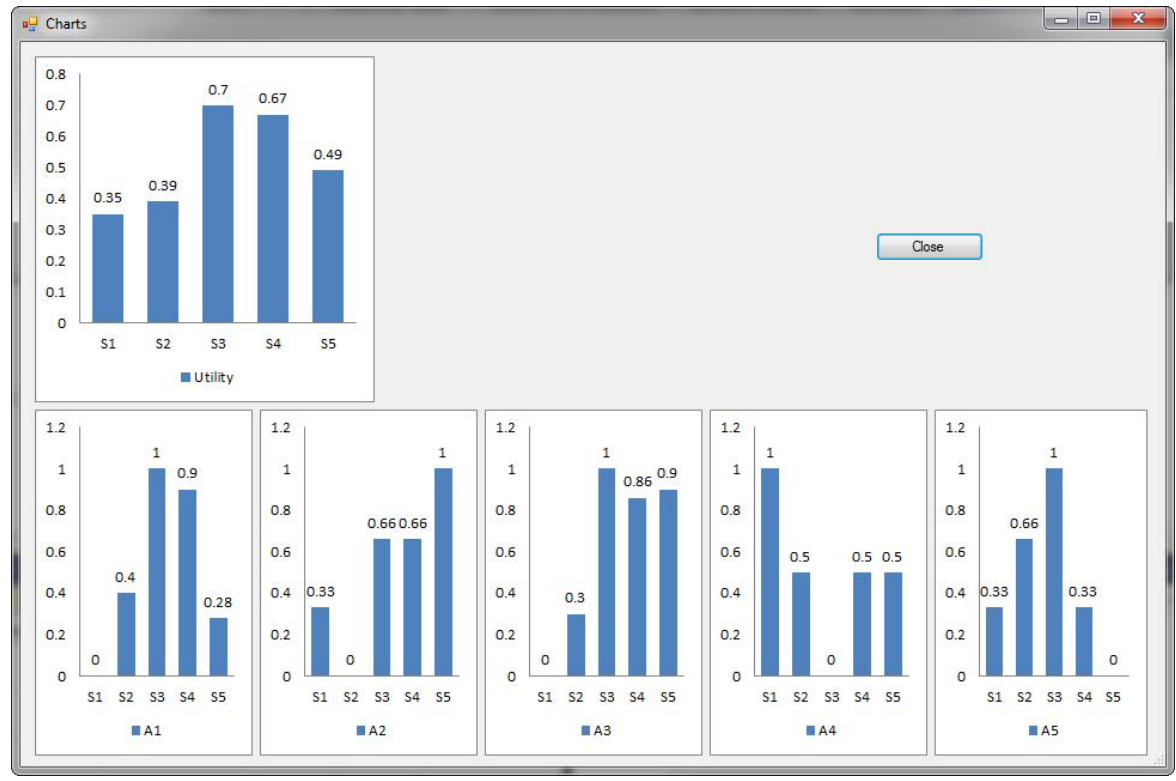

Fig. 9. Charts for total score and those for each attribute.

\section{Conclusions}

CADOProSys is user friendly and, from educational point of view is designed according to the curricula. Logistics module, with its component designed for suppliers selection reduce the time of this selection with almost $40 \%$, has no error of computation and it can dynamically adapt to requirements.

\section{References}

1. E. Frazelle. Supply chain strategy. The Logistics of Supply Chain Management. (McGraw-Hill PH., 2002)

2. Software Advice. http://www.softwareadvice.com/scm/logistics-comparison (automotive industry).

3. F. Harrison. Supply chain management workbook. (Butterworth Heinemann P.H, 2001)

4. E. Klimczak. Design for Software: A Playbook for Developers. (Wiley P.H., 2013)

5. P. Tchounikine. Computer science and educational software design (Springer, 2011)

6. H. Min. The Essentials of supply chain management new business concepts and applications. (Pearson P.H., 2015)

7. A. Langevin, D. Riopel. Logistics systems: design and optimisation. (Springer P.H., 2005)

8. J. Baron. Thinking and deciding. (Cambridge P.H., 2008)

9. S. Budidedu. Supplier selection by using multi criteria decision making methods. (LAP, 2015)

10. R. M. Garfamy. Supplier selection and business process improvement: an exploratory multiple case study. (LAP, 2010) 